\title{
Experimental Study and Numerical Solution of Poly Acrylic Acid Supported Magnetite Nanoparticles Transport in a One-Dimensional Porous Media
}

\author{
M. Golzar, ${ }^{1}$ S. F. Saghravani, ${ }^{1}$ and M. Azhdari Moghaddam ${ }^{2}$ \\ ${ }^{1}$ Department of Civil Engineering, University of Shahrood, Shahrood 3619995161, Iran \\ ${ }^{2}$ Department of Civil Engineering, University of Sistan and Baluchestan, Zahedan, Iran \\ Correspondence should be addressed to M. Golzar; golzarmohsen@yahoo.com
}

Received 3 March 2014; Revised 30 May 2014; Accepted 2 June 2014; Published 23 June 2014

Academic Editor: Zhaohui Li

Copyright (C) 2014 M. Golzar et al. This is an open access article distributed under the Creative Commons Attribution License, which permits unrestricted use, distribution, and reproduction in any medium, provided the original work is properly cited.

Recently, iron nanoparticles have attracted more attention for groundwater remediation due to its potential to reduce subsurface contaminants such as PCBs, chlorinated solvents, and heavy metals. The magnetic properties of iron nanoparticles cause to attach to each other and form bigger colloid particles of iron nanoparticles with more rapid sedimentation rate in aqueous environment. Using the surfactants such as poly acrylic acid (PAA) prevents iron nanoparticles from forming large flocs that may cause sedimentation and so increases transport distance of the nanoparticles. In this study, the transport of iron oxide nanoparticles $\left(\mathrm{Fe}_{3} \mathrm{O}_{4}\right)$ stabilized with PAA in a one-dimensional porous media (column) was investigated. The slurries with concentrations of 20,100 and $500(\mathrm{mg} / \mathrm{L})$ were injected into the bottom of the column under hydraulic gradients of $0.125,0.375$, and 0.625 . The results obtained from experiments were compared with the results obtained from numerical solution of advection-dispersion equation based on the classical colloid filtration theory (CFT). The experimental and simulated breakthrough curves showed that CFT is able to predict the transport and fate of iron oxide nanoparticles stabilized with PAA (up to concentration 500 ppm) in a porous media.

\section{Introduction}

There are various compositions of iron nanoparticles with wide range of applications in environmental engineering, especially in contaminant removal processes. One of the advantages of using iron nanoparticles for in situ processes is that they can be injected directly into the environment and contrary to millimetric iron particles, so there is no need for underground installation as in the case of permeable reactive barriers (PRBs) that makes it economically affordable [1]. Moreover, the extremely large specific surface area (SSA) of nanoparticles provides a much higher surface reactivity compared to the more widely used millimetric iron [2-4].

Nanoscale zerovalent iron (NZVI) has demonstrated high reactivity in remediation of aquifers contaminated by nonaqueous phase liquids, heavy metals, and other hazardous compounds. However, observations in laboratory and field scales disclosed the fact that the application of NZVI in porous media faces critical problems including short travel distances, pore plugging, and significant loss of porosity and permeability especially when used in high concentrations $[5,6]$. This is attributed to the strong tendency of NZVI bare particles to aggregation, agglomeration, and consequent rapid settlement or filtration on the solid phase surface [7]. Researches showed that bare iron nanoparticles may travel in porous media only a few centimeters from the injection point under typical groundwater conditions $[8,9]$. To overcome this limitation and to improve NZVI transport in porous media, researchers have used electrostatic, steric, and depletion stabilization mechanisms generating stabilized NZVI colloids by stabilizers like polystyrene sulfonate (PSS), carboxymethyl cellulose (CMC), poly acrylic acid (PAA), triblock, xanthan gum, and emulsified iron [10-15].

Phenrate et al. [16, 17] examined transport of polyelectrolyte-stabilized NZVI at different particle concentration $(0.03,0.3,1,3$ and $6 \mathrm{~g} / \mathrm{L})$ in saturated sand column. 
They demonstrated that slurry with low concentrations is in agreement with the assumptions of CFT model. In the slurries with higher concentrations $(C>1 \mathrm{~g} / \mathrm{L})$, they modified CFT model by providing empirical corrections. The empirical corrections are capable of estimating the agglomerate size and deposition during injection of slurry of polyelectrolytestabilized NZVI of high particle concentration in saturated sand $[16,17]$. In the CFT model, the removal of suspended particles is described by first-order kinetics, resulting in concentrations of suspended and retained particles that decay exponentially with distance $[18,19]$. In addition, other researchers such as Tosco et al. and Hosseini et al. [20, 21] developed another form of nanoparticles transport model that can be considered the pore blocking, clogging, and ripening processes during transport in porous media.

In addition to NZVI, iron oxide nanoparticles $\left(\mathrm{Fe}_{3} \mathrm{O}_{4}\right)$ can also be used in remedial processes for environmental engineering purposes. Although iron oxides nanoparticles have less reactivity than NZVI, the use of iron oxides nanoparticles, as powerful adsorbents and more stable to oxidation in groundwater treatment, provides a convenient approach for contaminant remediation. In addition, iron oxide nanoparticles can be easily separated and collected by applying external magnetic fields. $\mathrm{Hu}$ et al. [22] have used nanoparticles of iron oxide $\left(\mathrm{Fe}_{3} \mathrm{O}_{4}\right)$ in order to remove $\mathrm{Cr}(\mathrm{VI})$ from an aqueous media through absorption process. Also, Su and Puls and Yavuz et al. [23, 24] showed that iron oxides nanoparticles can be effective in the removal of arsenic from groundwater through the sorption of arsenite (As(III)) on the magnetite surface. Moreover, iron oxide nanoparticles were shown to be effective sorbents for a number of other heavy metals such as $\mathrm{Hg}, \mathrm{Ag}, \mathrm{Pb}, \mathrm{Cd}$, and $\mathrm{Ti}$ [25]. In addition, iron oxides nanoparticles can promote the transformation of carbon tetrachloride [26, 27]. Pan et al. [28] showed that iron oxides nanoparticles stabilized with sodium carboxymethyl cellulose can immobilize phosphorous in soils.

The objective of this study is to investigate the transport of iron oxide nanoparticles $\left(\mathrm{Fe}_{3} \mathrm{O}_{4}\right)$ stabilized with poly acrylic acid (PAA) in one-dimensional porous media. Transport tests in columns packed with glass beads were performed by injecting the iron oxide nanoparticles $\left(\mathrm{Fe}_{3} \mathrm{O}_{4}\right)$ stabilized with poly acrylic acid dispersed in deionized water with different concentrations $\left(C_{0}=20,100\right.$, and $\left.500 \mathrm{ppm}\right)$ and injection rates (hydraulic gradients $=0.125,0.375$, and 0.625 which represents 9 Darcian velocity due to the difference in viscosity of slurries). This research aimed to contribute to a better understanding of important parameters in the transport of the nanoparticles in porous media by providing the experimental data in order to evaluate the proposed model for nanoparticles transport. The experimental results were further analyzed by using a numerical one-dimensional model of advection-dispersion transport equation based on the classical colloid filtration theory (CFT).

\section{Methodology}

2.1. Materials. All chemicals used in these experiments were laboratory grade. Nano iron oxide $\left(\mathrm{Fe}_{3} \mathrm{O}_{4}\right)$ was obtained
From Pasteur Institute of Iran with 99.5\% purity and average particle size of 44.5 nanometers. For determination of particle size distribution of the nano iron oxide $\left(\mathrm{Fe}_{3} \mathrm{O}_{4}\right)$, particle size distribution test has been conducted. The results are shown in Figure 1(a). The existence of trivalent iron nanoparticles has been investigated using X-ray diffraction (XRD) device with $40 \mathrm{KV}$ energy, $30 \mathrm{~mA}$ current, and copper anodes and the results are presented in Figure 1(b). Poly acrylic acid (PAA, mean M.W. $=1.8 \mathrm{~kg} / \mathrm{mole}$ ) was purchased from Sigma Aldrich Company. Both materials (nano iron oxide $\left(\mathrm{Fe}_{3} \mathrm{O}_{4}\right)$ and poly acrylic acid) were in the powder form.

\subsection{Synthesize a Slurry of Iron Oxide Nanoparticles Stabilized} with PAA. Three slurries of iron oxide nanoparticles, with the concentrations of 20,100 , and $500 \mathrm{mg} / \mathrm{L}$ stabilized with poly acrylic acid. The optimum weight ratio of $2: 1$ (1 g nano iron oxide and $2 \mathrm{~g}$ poly acrylic acid) was selected based on findings by Saghravani et al. [29]. Preparation process included several steps as follows. The required iron oxide nanoparticles were placed in a flask and then distilled water was added up to one-fifth of the final volume of required slurry solution. The flask was put in an ultrasonic shaker (40 KHz frequency, $50 \mathrm{~W}$ power) for 5 periods of 6 minutes shaking and 1 minute rest to obtain a uniform mixture. Having PAA twice the weight of nano $\mathrm{Fe}_{3} \mathrm{O}_{4}$ in another flask, the remaining volume of distilled water was added to have the desired concentration and then placed on a shaker, $500 \mathrm{rpm}$ for 1 hour. The solutions were added to each other and placed in the ultrasonic shaker for another 1 hour. The result was a uniform solution of stabilized nano iron oxide with PAA. The solution was kept in the room temperature for another 24 hours and was shaken with an ultrasonic shaker for another half an hour before conducting the experiments. In order to specify the particle size distribution of iron oxide nanoparticles stabilized with PAA, samples were from the solutions of different concentrations. Using the particle size distribution test, the variation of amplitude and the average size of particles were specified. Figure 2 illustrates the particle size distribution in the samples. Zeta potential was measured in order to investigate the stability of the nanoparticles in the fluid. Since absolute value of zeta potential is greater than 30 for all samples $(|\zeta| \geq 30)$, it can be concluded that slurries of iron oxide nanoparticles stabilized with PAA were stable (Table 1). By summarizing the data provided in Table 1 and Figure 2 one can conclude that the size of particles would remain in the nano range after addition of PAA.

2.3. Porous Media. The experiments were conducted in a pyrex glass column with internal diameter of $3.5 \mathrm{~cm}$ and $40 \mathrm{~cm}$ height. The column was filled with glass bead $(8-20$ mesh, average diameter $d 50=1.8 \mathrm{~mm}$ ). Two porous glass diffuser plates with $1 \mathrm{~cm}$ height were placed on each end of pyrex glass column to provide an even distribution of iron oxide nanoparticles stabilized with PAA in the experiment column. The pore (void) volume was measured at $110 \mathrm{~mL}$ then the porosity was calculated to be 0.30 . For all tests, the column was prewashed with $2.2 \mathrm{~L}$ (20 times of pore volume) of 0.5 normal HCL and then washed through with distilled water 
TABLE 1: Average diameter of iron oxide nanoparticles stabilized with PAA and zeta potential ( $\zeta$ ) in slurries with concentrations (A) 20, (B) 100 , and (C) $500 \mathrm{mg} / \mathrm{L}$.

\begin{tabular}{lcc}
\hline Concentration $(\mathrm{mg} / \mathrm{L})$ & Average diameter of iron oxide nanoparticles stabilized with PAA $(\mathrm{nm})$ & Zeta potential $(\zeta)(\mathrm{mV})$ \\
\hline Bare nanoparticles & 44.52 & -23.88 \\
Nanoparticles stabilized with PAA & & -30.37 \\
$\quad 20$ & 85.14 & -46.44 \\
100 & 51.30 & -51.10 \\
500 & 48.99 & \\
\hline
\end{tabular}

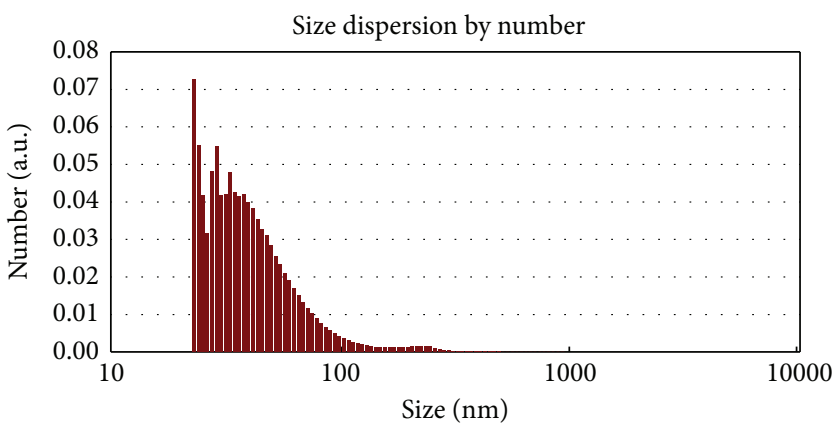

(a)

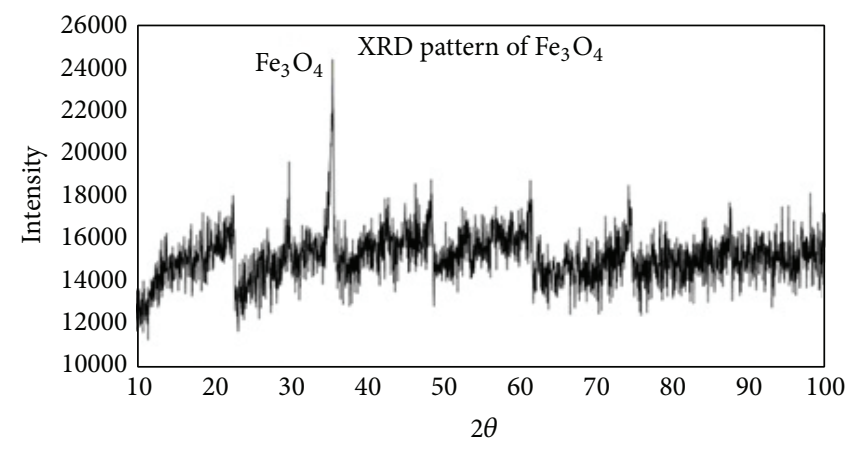

(b)

FIGURE 1: Diagram of size distribution of iron oxide nanoparticles $\left(\mathrm{Fe}_{3} \mathrm{O}_{4}\right)$ and the result of XRD analysis of iron oxide nanoparticles $\left(\mathrm{Fe}_{3} \mathrm{O}_{4}\right)$.

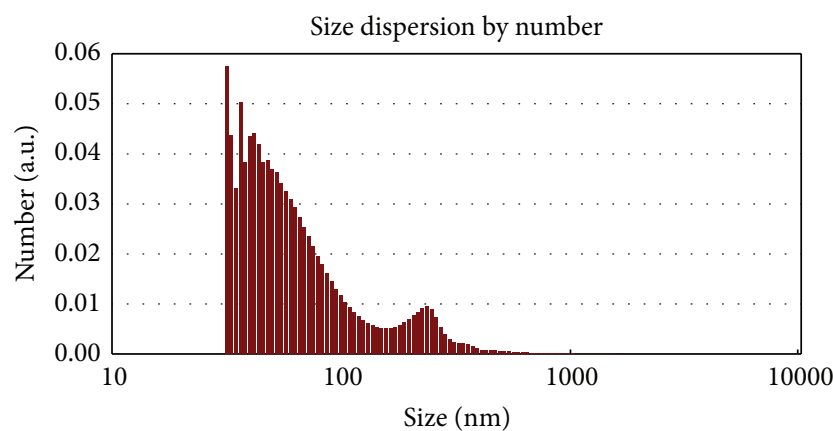

(a)

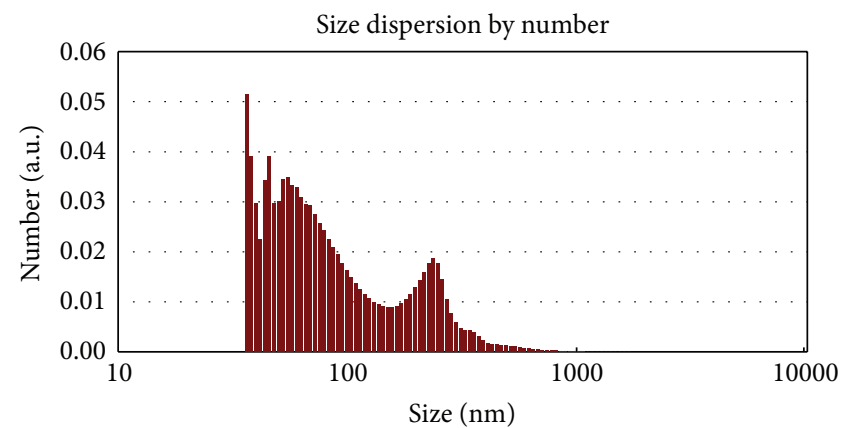

(b)

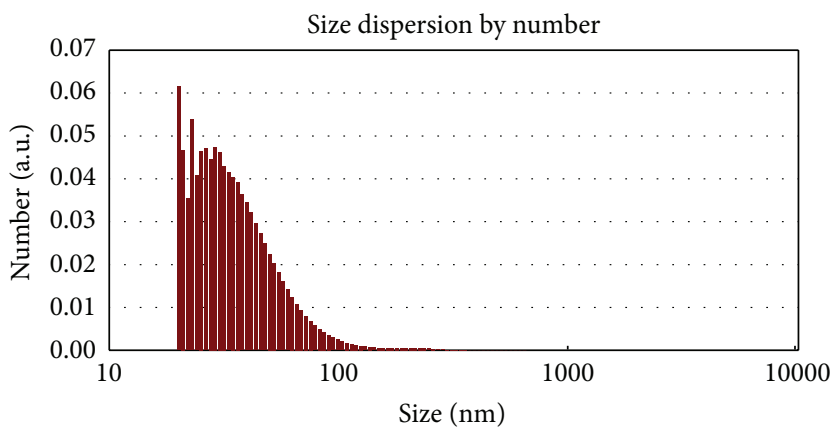

(c)

FIGURE 2: Diagram of size distribution of iron oxide nanoparticles stabilized with PAA in slurries with concentrations (a) 20, (b) 100, and (c) $500 \mathrm{mg} / \mathrm{L}$. 


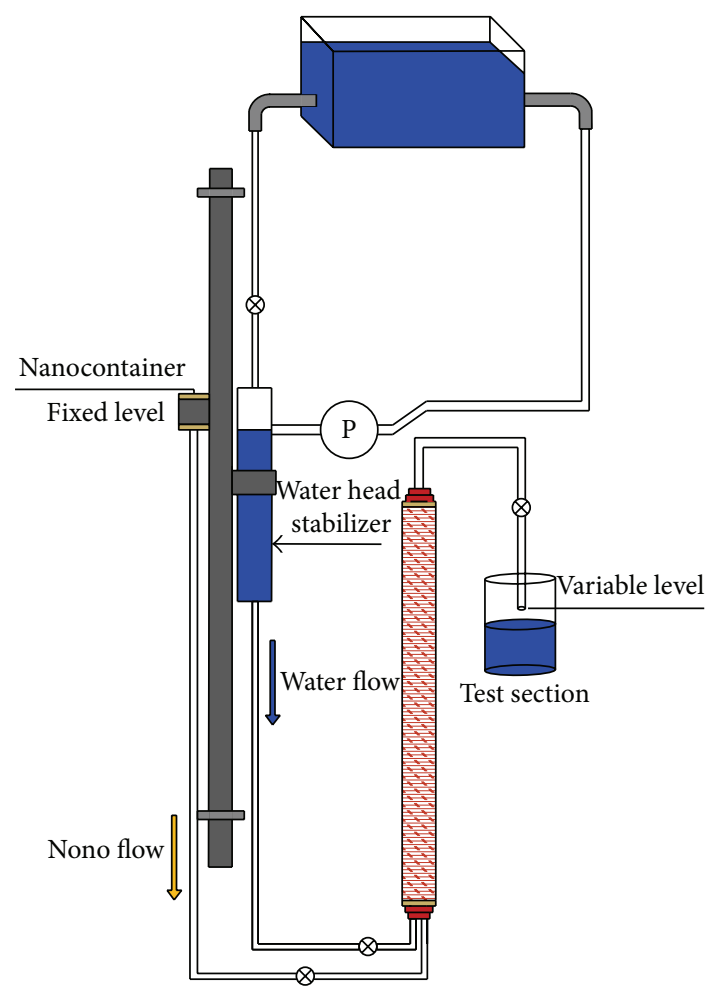

FIgURE 3: Schematic of the experimental setup.

until $\mathrm{pH}=7$ was confirmed in effulent so that we obtained a uniform, homogenous, and saturated porous media.

2.4. Transport Experiment. In these experiments $220 \mathrm{~mL}$ (approximately two times of empty pores volume) of iron oxide nano slurries stabilized with PAA (with different concentrations of 20,100, and $500 \mathrm{ppm}$ ) was injected to the porous media by applying hydraulic gradients equal to 0.125 , 0.375 , and 0.625 . The injections of water and slurry of iron oxide nanoparticles were made separately from the bottom of the column to avoid the errors due to trapped air bubbles. Simultaneously, from the beginning of the injection, samples were taken from the effluent at equal time intervals. Concentrations nanoparticles in the samples were measured through spectrophotometery by Jenus UV 1200-Spectrophotometer. The breakthrough curves for the concentration (of nanoparticles $\left(C / C_{0}\right)$ versus time) for all tests were then plotted (Figure 3). Each experiment was repeated three times and the breakthrough curves were provided based on the average of the concentration of samples.

2.5. The Advection-Dispersion Equation with Respect to Surface Absorption Conditions. The temporal and spatial variations of colloid concentration in a homogenous, granular porous media are described by the advection-dispersion equation:

$$
\frac{\partial C}{\partial t}=D \frac{\partial^{2} C}{\partial^{2} x}-U \frac{\partial C}{\partial t}
$$

Here, $C$ is the colloid concentration in the aqueous phase at a distance of $x$ and time $t, U$ is the interstitial particle velocity, and $D$ is the hydrodynamic dispersion coefficient. In (1), only the physical transport processes of advection and hydrodynamic dispersion are considered. In granular media, colloids are removed from the fluid-phase by physicochemical filtration or attachment to sediment grain surfaces. Physicochemical filtration of microbes has been modeled as either an irreversible (no detachment) or reversible process. In the case of reversible attachment, both equilibrium and kinetic mechanisms have been considered [30]. When an attachment mechanism is used to describe removal of particles from the liquid phase, the general equation for colloid transport and fate in a one-dimensional, homogeneous, granular porous media becomes

$$
\frac{\partial C}{\partial t}+\frac{\rho_{b}}{\varepsilon} \frac{\partial S}{\partial t}=D \frac{\partial^{2} C}{\partial^{2} x}-U \frac{\partial C}{\partial t},
$$

where $S$ is the retained particle concentration, $\rho_{b}$ is the dry bulk density of the porous media, and $\varepsilon$ is the porosity.

In the classical colloid filtration theory (CFT), originally presented in 1971 [30], the attachment of colloids to sediment surfaces is considered irreversible, neglecting the release of particles [31]. Thus the equation based on CFT can be written as

$$
\frac{\rho_{b}}{\varepsilon} \frac{\partial S}{\partial t}=K_{d} C
$$

where $K_{d}$ is the particles sedimentation rate coefficient (or the particle attachment rate coefficient). Considering the effect of the attachment of colloids to sediment surfaces, (2) for colloid transport and fate in a one-dimensional, homogeneous, granular porous media based on the classical colloid filtration theory (CFT) becomes

$$
D \frac{\partial^{2} C}{\partial x^{2}}-U \frac{\partial C}{\partial x}-K_{d} C=\frac{\partial C}{\partial t}
$$

where the particle attachment rate coefficient is related to $\eta_{0}$ and $\alpha$ via [18]. Consider

$$
K_{d}=\frac{3}{2} \frac{(1-\varepsilon) U}{d_{c}} \alpha \eta_{0} .
$$

Here, $d_{c}$ is the average sediment particles size. Due to limitations in the proposed theory for predicting the attachment efficiency $(\alpha)$, measurement techniques are usually employed instead [18]. The normalized fluid-phase colloid concentration $\left(C / C_{0}\right)$ at the length $x=L$ were calculated after the measured values of $C_{0}$ were obtained. Then the attachment efficiency $(\alpha)$ can be calculated using (6). In this work, the theoretical value of the single-collector contact efficiency $\left(\eta_{0}\right)$ was calculated by using a closed-form of the equation and data from Table $2[18,30]$. Consider

$$
\alpha=\frac{-2 d_{c}}{3(1-\varepsilon) L \eta_{0}} \ln \left(\frac{C}{C_{0}}\right) .
$$


TABLE 2: Required values of data for calculation of the single collector content efficiency $\left(\eta_{0}\right)$.

\begin{tabular}{|c|c|c|c|c|c|c|c|c|c|}
\hline \multirow{2}{*}{$d_{c}(\mathrm{~mm})$} & \multicolumn{3}{|c|}{$d_{p}(\mathrm{~nm})$} & \multirow{2}{*}{$A(\mathrm{j})$} & \multicolumn{3}{|c|}{$\mu(\mathrm{Pa} \cdot \mathrm{s})$} & \multirow{2}{*}{$P_{p}\left(\mathrm{~g} / \mathrm{cm}^{3}\right)$} & \multirow{2}{*}{$D_{\omega}\left(\mathrm{m}^{2} / \mathrm{s}\right)$} \\
\hline & $20(\mathrm{ppm})$ & $100(\mathrm{ppm})$ & $500(\mathrm{ppm})$ & & $20(\mathrm{ppm})$ & $100(\mathrm{ppm})$ & $500(\mathrm{ppm})$ & & \\
\hline 1.8 & 85.14 & 51.30 & 48.99 & $2.1 \times 10^{-19}$ & 0.0106 & 0.00713 & 0.0106 & 5.1 & $5.7 \times 10^{-13}$ \\
\hline
\end{tabular}

TABLE 3: The values of particles sedimentation rate coefficient $\left(K_{d}\right)$ and hydrodynamic dispersion coefficient $(D)$ calculated for each experiment.

\begin{tabular}{|c|c|c|c|c|c|c|c|c|}
\hline Test number & Concentration (ppm) & Density of slurry $\left(\mathrm{g} / \mathrm{cm}^{3}\right)$ & $\varepsilon$ & Hydraulic gradients & $U_{0}(\mathrm{~m} / \mathrm{s})$ & $C / C_{0}$ & $K_{d}(1 / \mathrm{s})$ & $D\left(\mathrm{~m}^{2} / \mathrm{s}\right)$ \\
\hline 1 & 20 & 1.005 & 0.3 & 0.125 & 0.000800 & 0.88 & 0.000256 & $9.000 \times 10^{-7}$ \\
\hline 2 & 20 & 1.005 & 0.3 & 0.375 & 0.001950 & 0.90 & 0.000514 & $1.020 \times 10^{-6}$ \\
\hline 3 & 20 & 1.005 & 0.3 & 0.625 & 0.002650 & 0.95 & 0.000340 & $2.500 \times 10^{-5}$ \\
\hline 4 & 100 & 1.021 & 0.3 & 0.125 & 0.000253 & 0.93 & 0.000046 & $9.250 \times 10^{-8}$ \\
\hline 5 & 100 & 1.021 & 0.3 & 0.375 & 0.000400 & 0.95 & 0.000051 & $1.000 \times 10^{-6}$ \\
\hline 6 & 100 & 1.021 & 0.3 & 0.625 & 0.001000 & 0.97 & 0.000076 & $2.000 \times 10^{-6}$ \\
\hline 7 & 500 & 1.045 & 0.3 & 0.125 & 0.000172 & 0.90 & 0.000045 & $7.500 \times 10^{-7}$ \\
\hline 8 & 500 & 1.045 & 0.3 & 0.375 & 0.000340 & 0.88 & 0.000109 & $1.500 \times 10^{-7}$ \\
\hline 9 & 500 & 1.045 & 0.3 & 0.625 & 0.000480 & 0.92 & 0.000100 & $1.750 \times 10^{-6}$ \\
\hline
\end{tabular}

Substituting (6) into (5), the particle attachment rate coefficient $\left(K_{d}\right)$ can be expressed in a simpler form as shown in the following:

$$
\begin{aligned}
K_{d} & =\frac{3}{2} \frac{(1-\varepsilon) U}{d_{c}} \alpha \eta_{0} \\
& =\frac{3}{2} \frac{(1-\varepsilon) U}{d_{c}} \times\left(\frac{-2 d_{c}}{3(1-\varepsilon) L \eta_{0}} \ln \left(\frac{C}{C_{0}}\right)\right) \times \eta_{0} \\
& =-\frac{U}{L} \times \ln \left(\frac{C}{C_{0}}\right) .
\end{aligned}
$$

To have an initial guess about hydrodynamic dispersion coefficient $(D)$ with regard to the experimental data plotted as a breakthrough curve, the method proposed by Charbeneau was employed [32]. In this method, the time values (on the abscissa) changed to a dimensionless parameter, $\xi$, and $\xi=(T-1) / \sqrt{2 T}$ and $T=t U / L . U$ is the interstitial particle velocity, $L$ is the length of the column, and $t$ is time from the beginning of the experiment. The breakthrough curves (BTC) then were redrawn with $\xi$ on abscissa and normalized fluid-phase colloid concentration at output column experiment $\left(C / C_{0}\right)$ on the ordinate. Initial approximate values for the hydrodynamic dispersion coefficients $(D)$ were obtained from (8) (Table 3). After having initial guess of value of hydrodynamic dispersion coefficient $(D)$, it was used as the initial value for the numerical solution of the advection-dispersion equation. The simulated and experimentally obtained breakthrough curves were plotted in the same diagram then any further justifications needed to reach to a match were performed. Consider

$$
D=\frac{U L}{4}\left(\xi_{0.84}-\xi_{0.16}\right) .
$$

Here, $\xi_{0.84}, \xi_{0.16}$ : the values of $\xi$ when the ratios $\left(C / C_{0}\right)$ are equal to 0.84 and 0.16 , respectively
2.5.1. Discretization Method and Numerical Solution of the Advection-Dispersion Equation. The transport equation for the classical colloid filtration theory (CFT) (4) was nondimensionalized as follows:

$$
\begin{array}{cc}
D^{*}=\frac{D}{L U_{0}}, & K_{d}^{*}=\frac{K_{d} L}{U_{0}}, \\
U^{*}=\frac{U}{U_{0}}, & C^{*}=\frac{C}{C_{0}}, \\
X^{*}=\frac{X}{L}, & t^{*}=\frac{t U_{0}}{L} .
\end{array}
$$

$U_{0}$ is the interstitial particle velocity, $L$ is the length of the column, $t$ is time from the beginning of the experiment, and $C_{0}$ is fluid-phase colloid concentration. Hence,

$$
D^{*} \frac{\partial^{2} C^{*}}{\partial x^{* 2}}-U^{*} \frac{\partial C^{*}}{\partial x^{*}}-K_{d}^{*} C^{*}=\frac{\partial C^{*}}{\partial t^{*}} .
$$

Laasonen method, which is unconditionally stable, was employed to solve (10). The Laasonen method uses the second-order central difference approximation for space derivatives and the first-order forward approximation for time derivate. With discretization of derivatives and further simplifications, (10) was converted to (11) which was solved through tridiagonal system of equations by applying appropriate boundary and initial conditions for each experiment. The results of the numerical solutions were drawn accordingly [33]. Consider

$$
\begin{aligned}
& {\left[-\frac{D^{*} \Delta t^{*}}{\Delta x^{* 2}}-\frac{U^{*} \Delta t^{*}}{2 \Delta x^{*}}\right] C_{i-1}^{* n+1}} \\
& +\left[1+\frac{2 D^{*} \Delta t^{*}}{\Delta x^{* 2}}+K_{d}^{*} \Delta t^{*}\right] C_{i}^{* n+1} \\
& +\left[-\frac{D^{*} \Delta t^{*}}{\Delta x^{* 2}}+\frac{U^{*} \Delta t^{*}}{2 \Delta x^{*}}\right] C_{i+1}^{* n+1}=C_{i}^{* n} .
\end{aligned}
$$




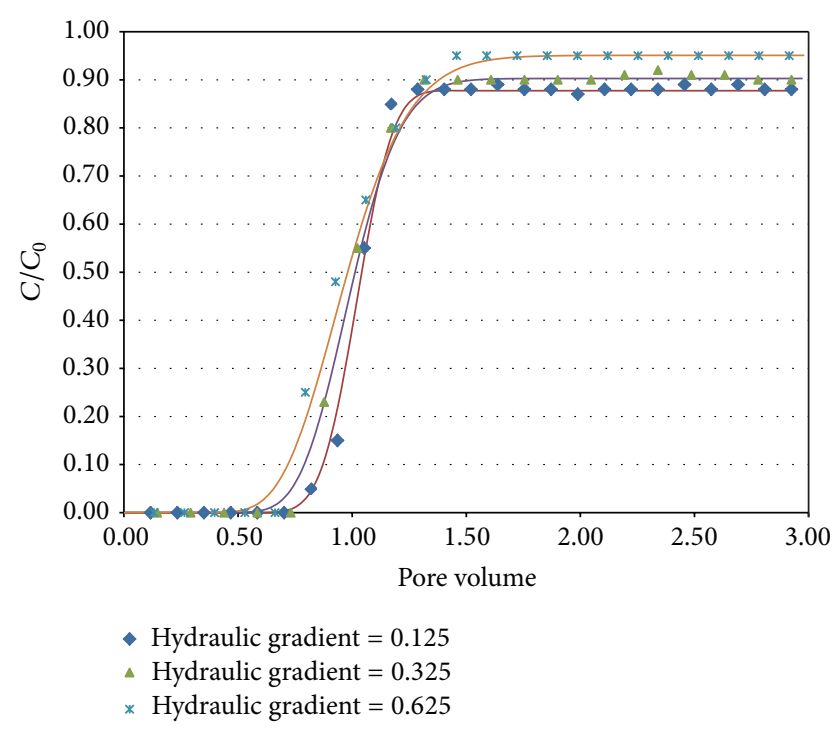

Figure 4: The normalized breakthrough curves $\left(C / C_{0}\right)$ of iron oxide slurry stabilized with poly acrylic acid at concentration $20 \mathrm{ppm}$. Colored symbols and lines indicate the observed and simulated values, respectively.

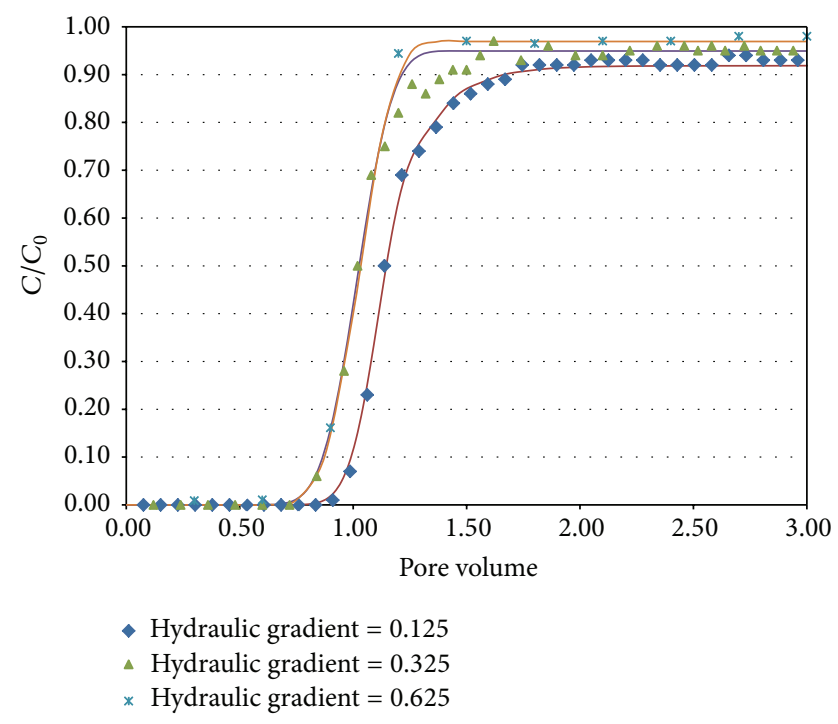

Figure 5: The normalized breakthrough curves $\left(C / C_{0}\right)$ of iron oxide slurry stabilized with poly acrylic acid at concentration $100 \mathrm{ppm}$. Colored symbols and lines indicate the observed and simulated values, respectively.

\section{Results}

Figures 4, 5, and 6 demonstrate the breakthrough curves obtained from the experiments of transport of iron oxide slurry stabilized with PAA, in different concentrations under variety of hydraulic gradients along with the simulated breakthrough curves obtained from numerical solution of the advection-dispersion equation with corresponding initial and appropriate boundary conditions for each experiment. All breakthrough curves, obtained from laboratory tests

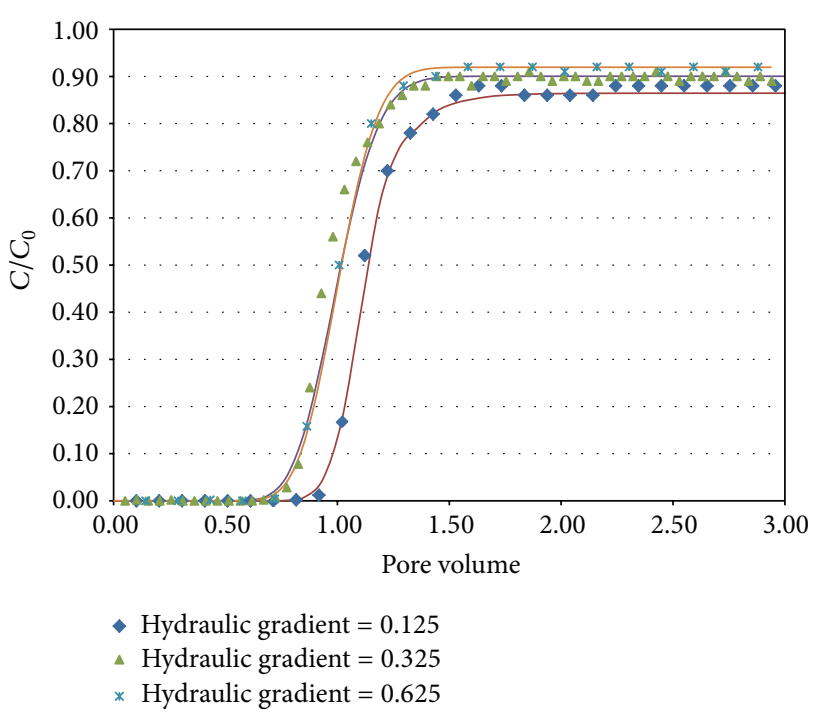

FIgURE 6: The normalized breakthrough curves $\left(C / C_{0}\right)$ of iron oxide slurry stabilized with poly acrylic acid at concentration $500 \mathrm{ppm}$. Colored symbols and lines indicate the observed and simulated values, respectively.

and the numerical simulations, are in a good agreement which indicates the classical colloid filtration theory (CFT) has the ability of prediction of the transport and fate of iron oxide nanoparticles $\left(\mathrm{Fe}_{3} \mathrm{O}_{4}\right)$ stabilized with poly acrylic acid. As seen in Figures 4-6 an increase in the hydraulic gradients of injection of slurry inflow into the experiment column, causes the increase in the ratio of $\left(C / C_{0}\right)$ in the outflow from the experiment column. The agglomerate size is a result of the balance between van der Waals forces and magnetic attractions between iron oxide nanoparticles, electrostatic repulsive forces from the adsorbed PAA, and the induced fluid shear in the pore spaces. The agglomerates then transport and deposit onto a surface of collector (e.g., a sand grain). The agglomerates with large size yield higher attachment efficiency because the drag force due to the fluid flow (which promotes detachment) is less than the adhesive force which promotes particle attachment when the size of the retained particles/agglomerates increases. Increasing the hydraulic gradients of slurry inflow to the experiment column (increasing injection rates) reduces the possibility of the formation of large agglomerate due to higher shear force applied from the fluid. Hence in a high-speed flow field the size of agglomerates is less than in low-speed flow fields. Increasing injection rates lead to greater drag forces of the fluid therefore causes more absorbed agglomerates remove of surface of collectors, and it can lead to increase of ratio of $\mathrm{C} / \mathrm{C}_{0}$ at outflow.

\section{Conclusions}

In this study, the transport of iron oxide nanoparticles $\left(\mathrm{Fe}_{3} \mathrm{O}_{4}\right)$ stabilized with poly acrylic acid in saturated porous media under different hydraulic heads was investigated. Based on the characterizations of the slurry, breakthrough 
tests, and numerical simulation, the following conclusions can be made.

(1) A good prediction of transport and fate of iron oxide nanoparticles $\left(\mathrm{Fe}_{3} \mathrm{O}_{4}\right)$, stabilized with poly acrylic acid in a $1 \mathrm{D}$ porous media, can be obtained from numerical solution of advection-dispersion equation based on the classical colloid filtration theory (CFT).

(2) The particles sedimentation rate coefficient $\left(K_{d}\right)$ can be calculated based on the CFT to predict the effluent concentration of the slurry.

(3) Increasing hydraulic gradient causes the rate of media absorption to decrease, which in turn makes its transfer to the polluted area more feasible.

(4) The capability of Charboneau's method for prediction of hydrodynamic dispersion coefficient $(D)$ was verified for slurries.

\section{Conflict of Interests}

The authors declare that there is no conflict of interests regarding the publication of this paper.

\section{References}

[1] E. K. Wilson, "Zero-valent metals provide possible solution to groundwater problems," Chemical and Engineering News, vol. 73, no. 27, pp. 19-23, 1995.

[2] W.-X. Zhang, "Nanoscale iron particles for environmental remediation: an overview," Journal of Nanoparticle Research, vol. 5, no. 3-4, pp. 323-332, 2003.

[3] X. Li, P. Zhang, C. L. Lin, and W. P. Johnson, "Role of hydrodynamic drag on microsphere deposition and re-entrainment in porous media under unfavorable conditions," Environmental Science and Technology, vol. 39, no. 11, pp. 4012-4020, 2005.

[4] F. S. Freyria, B. Bonelli, R. Sethi, M. Armandi, E. Belluso, and E. Garrone, "Reactions of acid orange 7 with iron nanoparticles in aqueous solutions," Journal of Physical Chemistry C, vol. 115, no. 49, pp. 24143-24152, 2011.

[5] K. J. Cantrell, D. I. Kaplan, and T. J. Gilmore, "Injection of colloidal $\mathrm{Fe} 0$ particles in sand with shear-thinning fluids," Journal of Environmental Engineering, vol. 123, no. 8, pp. 786791, 1997.

[6] J. Zhan, T. Zheng, G. Piringer et al., "Transport characteristics of nanoscale functional zerovalent iron/silica composites for in situ remediation of trichloroethylene," Environmental Science and Technology, vol. 42, no. 23, pp. 8871-8876, 2008.

[7] T. Phenrat, N. Saleh, K. Sirk, R. D. Tilton, and G. V. Lowry, "Aggregation and sedimentation of aqueous nanoscale zerovalent iron dispersions," Environmental Science and Technology, vol. 41, no. 1, pp. 284-290, 2007.

[8] A. Tiraferri, K. L. Chen, R. Sethi, and M. Elimelech, "Reduced aggregation and sedimentation of zero-valent iron nanoparticles in the presence of guar gum," Journal of Colloid and Interface Science, vol. 324, no. 1-2, pp. 71-79, 2008.

[9] E. D. Vecchia, M. Coisson, C. Appino, F. Vinai, and R. Sethi, "Magnetic characterization and interaction modeling of zerovalent iron nanoparticles for the remediation of contaminated aquifers," Journal of Nanoscience and Nanotechnology, vol. 9, no. 5, pp. 3210-3218, 2009.
[10] N. D. Berge and C. A. Ramsburg, "Oil-in-water emulsions for encapsulated delivery of reactive iron particles," Environmental Science and Technology, vol. 43, no. 13, pp. 5060-5066, 2009.

[11] S. Comba and R. Sethi, "Stabilization of highly concentrated suspensions of iron nanoparticles using shear-thinning gels of xanthan gum," Water Research, vol. 43, no. 15, pp. 3717-3726, 2009.

[12] F. He, D. Zhao, J. Liu, and C. B. Roberts, "Stabilization of Fe-Pd nanoparticles with sodium carboxymethyl cellulose for enhanced transport and dechlorination of trichloroethylene in soil and groundwater," Industrial and Engineering Chemistry Research, vol. 46, no. 1, pp. 29-34, 2007.

[13] S. R. Kanel, R. R. Goswami, T. P. Clement, M. O. Barnett, and D. Zhao, "Two dimensional transport characteristics of surface stabilized zero-valent iron nanoparticles in porous media," Environmental Science and Technology, vol. 42, no. 3, pp. 896900, 2008.

[14] T. Phenrat, H.-J. Kim, F. Fagerlund, T. Illangasekare, R. D. Tilton, and G. V. Lowry, "Particle size distribution, concentration, and magnetic attraction affect transport of polymermodified Fe0 nanoparticles in sand columns," Environmental Science and Technology, vol. 43, no. 13, pp. 5079-5085, 2009.

[15] N. Saleh, T. Phenrat, K. Sirk et al., "Adsorbed triblock copolymers deliver reactive iron nanoparticles to the oil/water interface," Nano Letters, vol. 5, no. 12, pp. 2489-2494, 2005.

[16] T. Phenrat, A. Cihan, H.-J. Kim, M. Mital, T. Illangasekare, and G. V. Lowry, "Transport and deposition of polymer-modified $\mathrm{Fe} 0$ nanoparticles in 2-D heterogeneous porous media: effects of particle concentration, Fe 0 content, and coatings," Environmental Science and Technology, vol. 44, no. 23, pp. 9086-9093, 2010.

[17] T. Phenrat, H.-J. Kim, F. Fagerlund, T. Illangasekare, and G. V. Lowry, "Empirical correlations to estimate agglomerate size and deposition during injection of a polyelectrolyte-modified $\mathrm{Fe} 0$ nanoparticle at high particle concentration in saturated sand," Journal of Contaminant Hydrology, vol. 118, no. 3-4, pp. 152-164, 2010.

[18] N. Tufenkji and M. Elimelech, "Correlation equation for predicting single-collector efficiency in physicochemical filtration in saturated porous media," Environmental Science and Technology, vol. 38, no. 2, pp. 529-536, 2004.

[19] S. C. Kim, M. S. Harringto n, and D. Y. H. Pui, "Experimental study of nanoparticles penetration through commercial filter media," Journal of Nanoparticle Research, vol. 9, pp. 117-125, 2007.

[20] T. Tosco and R. Sethi, "Transport of non-newtonian suspensions of highly concentrated micro- and nanoscale iron particles in porous media: a modeling approach," Environmental Science and Technology, vol. 44, no. 23, pp. 9062-9068, 2010.

[21] S. M. Hosseini and T. Tosco, "Transport and retention of high concentrated nano-Fe/Cu particles through highly flow-rated packed sand column," Water Research, vol. 47, no. 1, pp. 326338,2013

[22] J. Hu, G. Chen, and I. M. C. Lo, "Selective removal of heavy metals from industrial wastewater using maghemite nanoparticle: performance and mechanisms," Journal of Environmental Engineering, vol. 132, no. 7, pp. 709-715, 2006.

[23] C. Su and R. W. Puls, "Arsenate and arsenite sorption on magnetite: relations to groundwater arsenic treatment using zerovalent iron and natural attenuation," Water, Air, and Soil Pollution, vol. 193, no. 1-4, pp. 65-78, 2008. 
[24] C. T. Yavuz, J. T. Mayo, W. W. Yu et al., "Low-field magnetic separation of monodisperse $\mathrm{Fe}_{3} \mathrm{O}_{4}$ nanocrystals," Science, vol. 314, no. 5801, pp. 964-967, 2006.

[25] W. Yantasee, C. L. Warner, T. Sangvanich et al., "Removal of heavy metals from aqueous systems with thiol functionalized superparamagnetic nanoparticles," Environmental Science and Technology, vol. 41, no. 14, pp. 5114-5119, 2007.

[26] M. L. McCormick and P. Adriaens, "Carbon tetrachloride transformation on the surface of nanoscale biogenic magnetite particles," Environmental Science and Technology, vol. 38, no. 4, pp. 1045-1053, 2004.

[27] P. J. Vikesland, A. M. Heathcock, R. L. Rebodos, and K. E. Makus, "Particle size and aggregation effects on magnetite reactivity toward carbon tetrachloride," Environmental Science and Technology, vol. 41, no. 15, pp. 5277-5283, 2007.

[28] G. Pan, L. Li, D. Zhao, and H. Chen, "Immobilization of nonpoint phosphorus using stabilized magnetite nanoparticles with enhanced transportability and reactivity in soils," Environmental Pollution, vol. 158, no. 1, pp. 35-40, 2010.

[29] S. F. Saghravani, F. Daneshgar, and M. Golzar, "Investigation on stability of slurry of iron oxide nanoparticles $\left(\mathrm{Fe}_{3} \mathrm{O}_{4}\right)$ stabilized with poly acrylic acid," in Proceedings of the 7th National Congress on Civil Engineering, Shahid Nikbakht Faculty of Engineering, Zahedan, Iran, 2013.

[30] K.-M. Yao, M. T. Habibian, and C. R. O'Melia, "Water and waste water filtration: concepts and applications," Environmental Science and Technology, vol. 5, no. 11, pp. 1105-1112, 1971.

[31] N. Tufenkji and M. Elimelech, "Deviation from the classical colloid filtration theory in the presence of repulsive DLVO interactions," Langmuir, vol. 20, no. 25, pp. 10818-10828, 2004.

[32] R. J. Charbeneau, Groundwater Hydraulics and Pollutant Transport, Waveland Press, 2008.

[33] K. A. Hoffmann and S. T. Chiang, Computational Fluid Dynamics, vol. 1, Engineering Education System, 2000. 

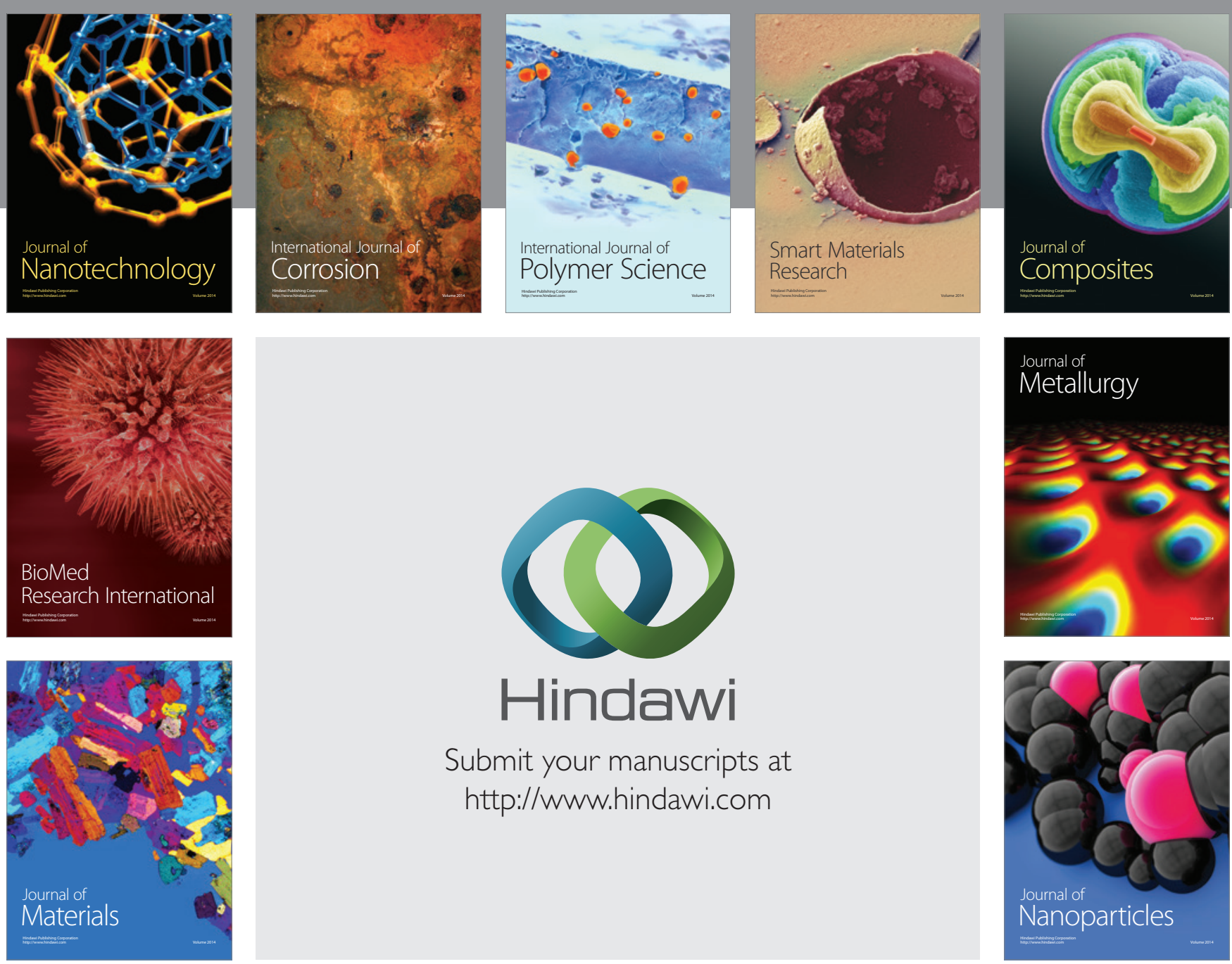

Submit your manuscripts at http://www.hindawi.com
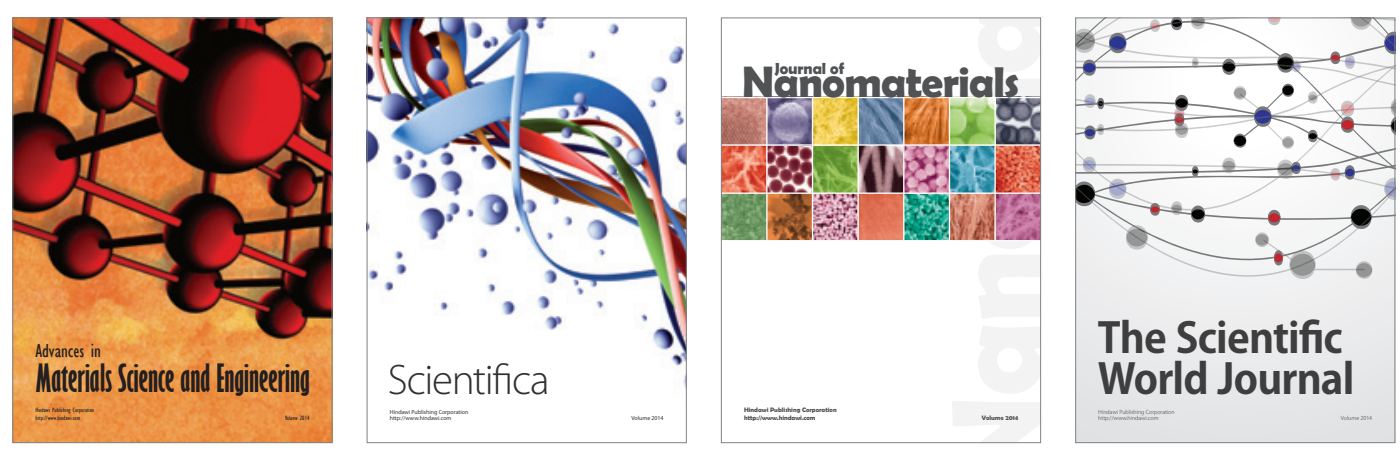

\section{The Scientific World Journal}
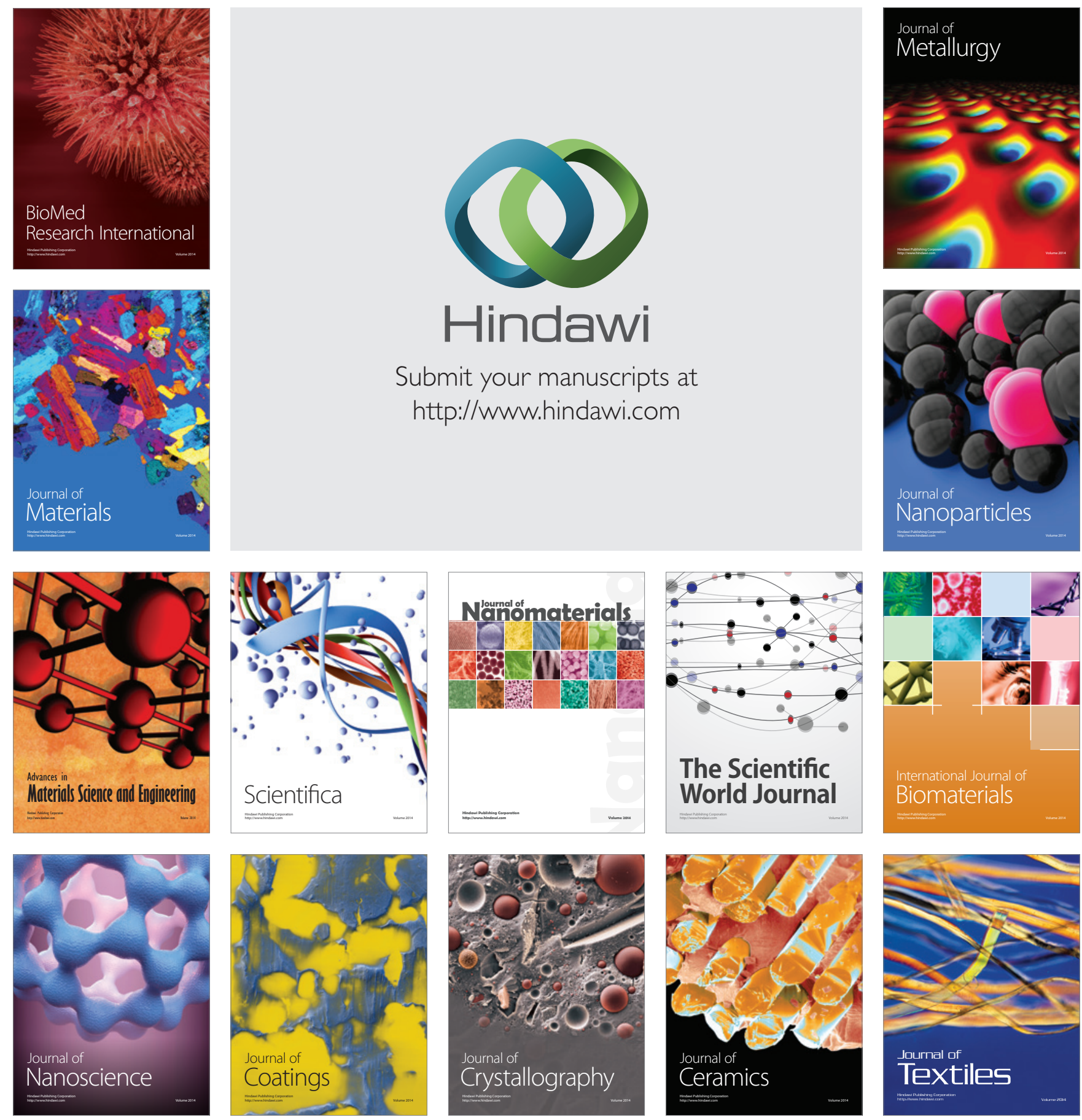